\title{
Awareness of COVID-19, Protective Measures and Attitude Towards Vaccination among University of Jeddah Health Field Community: A Questionnaire- Based Study
}

\author{
Almonther A. Hershan ${ }^{1,2}$ (D) \\ ${ }^{1}$ Department of Medical Microbiology and Parasitology, Faculty of Medicine, University of Jeddah, \\ Jeddah, Saudi Arabia. \\ ${ }^{2}$ Department of Medical Lab Technology, Faculty of Applied Medical Sciences, No. 23218, \\ Hamza Bin Elgasim Road, Alsharafya, University of Jeddah, Jeddah, Saudi Arabia.
}

\begin{abstract}
This cross-sectional study aimed to measure the awareness, and attitude towards COVID-19 disease as well as new vaccine acceptance, among health field community (healthcare workers, health fields teaching staff and students) at the University of Jeddah, Jeddah Saudi Arabia. The questionnaire was designed in English language and included a set of $\mathbf{4 4}$ multiple-choice close-ended questions that covered demographic profile of participants, awareness of symptoms and practice against COVID-19. It also included a set of questions that attempted to investigate the attitudes and perceptions towards the uptake of vaccine. Out of the total 186 who participated in this study, $48.4 \%$ were 24 years old or younger and $\mathbf{5 5 . 9 \%}$ were health field students. The results showed that majority of participants were aware of most common symptoms and causes of COVID-19 and had positive attitude toward the protective measures against the disease. Regarding the acceptability of vaccination against COVID-19, around $44 \%$ of the total participants showed hesitancy to uptake the vaccine of whom, $68.3 \%$ were concerned about the adverse effects of the vaccine. Significant differences were found between gender and current position at university of Jeddah in term of vaccine acceptance with p-values of $<0.001$. Despite this high level of awareness, health field community at the university of Jeddah have medium acceptance level of disease vaccine. Thus, health educational programs are important to increase the acceptance level among such societies which will contribute to increase the acceptance level among the whole society.
\end{abstract}

Keywords: Health field community, COVID-19, Awareness, Vaccine, University of Jeddah

*Correspondence: ahershan@uj.edu.sa; +966 503787877

(Received: February 04, 2021; accepted: March 08, 2021)

Citation: Hershan AA. Awareness of COVID-19, Protective Measures and Attitude Towards Vaccination among University of Jeddah Health Field Community: a Questionnaire-Based Study. J Pure App/ Microbiol. 2021;15(2):604-612. doi: 10.22207/JPAM.15.2.02

(C) The Author(s) 2021. Open Access. This article is distributed under the terms of the Creative Commons Attribution 4.0 International License which permits unrestricted use, sharing, distribution, and reproduction in any medium, provided you give appropriate credit to the original author(s) and the source, provide a link to the Creative Commons license, and indicate if changes were made. 


\section{INTRODUCTION}

The newly discovered Coronavirus disease (COVID-19) is one of the deadly infectious diseases that harm world population ${ }^{1}$. This severe acute respiratory syndrome coronavirus COVID-19' pandemic has been infecting more than 64 million over 218 countries ${ }^{2,3}$.

It has been confirmed that the newly discovered COVID-19 spreads mainly from person to another through respiratory droplets contact with mucus membrane ${ }^{4}$. The virus was also reported to be robustly transmitted by asymptomatic persons during the virus incubation ${ }^{5}$ and can stay on materials up to 5 days depending on the type of contaminated material, thus it was found to spread via direct contact with contaminated surfaces ${ }^{6-8}$.

Based on current literature, COVID-19 is considered as a highly infectious disease that induces primary symptoms such as fever, difficulty in breathing, dry coughing, fatigue, headache, and throat congestions $\mathrm{s}^{9,10}$. The severity of symptoms has shown to be different from person to person and more severe in elderlies, especially those with other chronic health conditions ${ }^{11}$.

Globally, COVID-19 pandemic induced an international crisis at various levels including social, economic, and business areas. Therefore, Extreme prevention criteria have been followed by most of countries to reduce the effects of the disease that include self-isolation, prevent public gathering, imposing social distancing, closing schools and universities, closing borders and in some cases, complete cities lockdown. Additionally, governments and non-governmental organizations introduced day by day updates to improve awareness of preventive measures and controls though frequent hand washes and usage of masks and gloves.

The first positive case in Saudi Arabia was reported by the Ministry of Health on second of March 2020, and the number multiplied in the country within few months, making a critical challenge for healthcare professionals ${ }^{12}$. The number of affected cases is around 365 thousand (as for $11^{\text {th }}$ January 2021). The total number is expected to raise as the disease is still spreading [13]. The fight against COVID-19 depends heavily on knowledge, attitude, and adherence towards the protective measures as well as the personal decision to vaccinate against the disease. Health care workers, medical field students and their trainers are at increased risk of getting the disease, and in return, their safety and awareness are needed in order to provide medical care for COVID-19 patients as well as preventing the transmission of the virus to other individuals. Thus, this study designed to understand the extent of generalized attitude toward protective measures needs to be implemented to stand against the pandemic as well as vaccine acceptance towards forthcoming coronavirus vaccines among healthcare workers, health fields teaching staff and students at University of Jeddah.

\section{METHODS \\ Study design}

This is a cross-sectional web-based study conducted using an online survey that was distributed to health field community at University of Jeddah between December 5th and December $25^{\text {th }}$ of the year 2020 . The online questionnaire was designed using Google Forms and sent through the official social media channels of societies and associations representing the following practitioners: health workers, teaching staff (including medicine and applied medical sciences staff, and healthcare workers), lab technicians and health field students; collectively termed as health field participants at University of Jeddah.

All health field community practicing in University of Jeddah and were eligible to participate in the study. Participants who did not agree to the terms of the electronic consent form presented at the beginning of questionnaire as well as those who did not complete the survey were excluded from the analysis.

\section{The questionnaire}

Based on the questionnaires developed by WHO on emerging respiratory viruses, including COVID-192 ${ }^{2}$ the first part of the study questionnaire was adopted. Beside the questions about the knowledge of symptoms and practical attitude towards the protective measures, additional questions on perception toward COVID-19 vaccination were also driven from vaccine questionnaires that published by World Health Organization (WHO). These questionnaires were 
already validated, and its reliability was also previously tested through number of published reports $^{14,15,16}$.

The questionnaire was delivered in English language and included a set of 44 multiplechoice close-ended questions that covered sociodemographic characteristics of participants, knowledge of symptoms and signs, precautions against COVID-19, and attitudes and perceptions towards the uptake of vaccine.

\section{Data analysis}

Data analysis performed using SPSS software version 25 (IBM Corporation, Armonk, NY, USA). Descriptive analysis was conducted to generate summary tables for sociodemographic profile of participants and the study variables. Crosstabulation analysis was also performed to examine the distribution of intention to uptake COVID-19 with participants' sociodemographic characteristics using chi-squared tests, MannWhitney (2independent groups) and Kruskal-Wallis (more than 2 independent groups) tests. P-value of less than 0.05 was considered as statistically significant.

\section{RESULTS}

\section{Participants demographics}

Out of the total number (701) of health field community at University of Jeddah, 186 (26.55) participants opted to complete the survey.
Almost half of the participants were 24 years old or younger ( $n=90,48.4 \%$ ), with more than half of the respondents being health field students ( $n=104,55.9 \%)$ and $73.15 \%(n=136)$ being males (Table 1).

Knowledge of COVID-19 terminology, symptoms, and protection measures

Descriptive analysis showed that around $80 \%$ of participants were aware about the scientific name of the virus causing COVID-19 and 58\% were aware about the source of emergence of the SARS-CoV-2. Regarding the participants' general awareness level about the disease, 154 (82.8\%) reported that they had good and very good level of awareness (Table 2).

The analysis of this part also showed that the majority of participants were aware of most of symptoms and signs of COVID-19. Nevertheless, more than one-third of them were not sure or disagreed that diarrhoea and nasal congestion are symptoms of the disease. In addition, more than half of participants (57\%) either were not certain or disagreed with the vomiting as a symptom of COVID-19. Almost all of participants were aware of measures that should be taken to protect against infection with COVID-19. Concerning health and safety precautions that people are expected to follow, almost more than $90 \%$ of participants reported that they are avoiding travelling to infected areas, using public transports, shaking

Table 1. Sociodemographic characteristics of participants $(n=186)$

\begin{tabular}{llll}
\hline Characteristic & Category & Frequency & $\%$ \\
\hline Age group & $18-24$ & 90 & $48 \%$ \\
(years) & $25-31$ & 20 & $10.8 \%$ \\
& $32-38$ & 30 & $16.1 \%$ \\
& $39-46$ & 32 & $17.2 \%$ \\
Gender & $\geq 47$ & 14 & $7.5 \%$ \\
Highest education & Males & 136 & 73.15 \\
level & Females & 50 & $26.9 \%$ \\
& High school & 20 & $10.8 \%$ \\
& Diploma & 4 & $2.2 \%$ \\
& Bachelor's & 78 & $41.9 \%$ \\
Current position & Masters & 18 & $9.7 \%$ \\
& PhD or equivalent & 66 & $35.5 \%$ \\
& Teaching staff (medicine) & 34 & $18.3 \%$ \\
& Teaching staff (AMS) & 36 & $19.4 \%$ \\
& Healthcare worker & 6 & $3.2 \%$ \\
& Lab technician & 6 & $3.2 \%$ \\
& Health field student & 104 & $55.9 \%$ \\
\hline
\end{tabular}


hands, and forcing themselves to wear the face mask since the pandemic starts to enter the country. However, many were not sure about the importance of taking herbal supplements (53.3\%), avoid stress ( $24.7 \%)$, sufficient sleeping (22.6\%), eating a balanced diet (21.5\%) and regular exercises $(20.4 \%)$ in boosting immunity against the virus (Fig. 1).

\section{Attitude of participants towards vaccination Attitudes toward general vaccine}

This part of analysis was divided into two sections: section A dealt with responses to 5 questions about vaccination (overall) and section $B$ dealt with responses to 3 questions about COVID-19 vaccine (Table 3 ). Out of all participants $(n=186)$, around $80 \%$ reported that vaccination is important for the protection of public health, $75 \%$ reported that it is a good way to protect themselves from diseases, however, $70 \%$ and $60 \%$ were aware that vaccinations are effective and safe, respectively. Regarding seasonal flu vaccine, $67 \%$ of participants reported that they had the vaccine before.

\section{Attitudes toward COVID-19 vaccine}

Responses to questions designed to assess the acceptance of COVID-19 vaccine (question 6-7) yielded that $53.8 \%$ were not confident about the scientific venting processes for the novel coronavirus/ COVID-19 vaccine and $44.1 \%$ will not or were not sure to take the vaccine if it becomes available in Saudi Arabia and being recommended (Table 3). Out of the 82 participants who were asked about the reason of rejecting or hesitancy to take the vaccine, $68.3 \%$ were concerned about the adverse effects of the vaccine, $29.3 \%$ claimed that the new vaccine might not be safe, however, only $2.4 \%$ stated that the vaccine might not work (Fig. 2).

Around $65 \%$ of male participants and $69 \%$ of those who were aged between 39 and 46 years accepted to take the COVID-19 vaccine if being available and recommended. Hundred percent of healthcare workers and $88.2 \%$ of medicine teaching staff showed interest in up taking the vaccine. Further analysis using Mann-Whitney and Kruskal-Wallis tests were carried to find

Table 2. Awareness of participants regarding the scientific name of the virus causing COVID-19 and the cause of emergence of SARS-CoV- $2^{*}(n=186)$.

\begin{tabular}{lcccc}
\hline & & Yes & No & Not Sure \\
\hline Awareness of the scientific name & Frequency $(\mathrm{n})$ & 148 & 20 & 18 \\
of the virus casing COVID-19 & Percent $(\%)$ & 79.6 & 10.8 & 9.7 \\
Awareness of the cause of & Frequency (n) & 108 & 40 & 38 \\
emergence of SARS-COV-2 & Percent (\%) & 58.1 & 21.5 & 20.4 \\
\hline
\end{tabular}

Table 3. Participants responses toward general vaccination and COVID-19 vaccine $(n=186)$

\begin{tabular}{|c|c|c|c|c|}
\hline \multirow[t]{2}{*}{ Section } & \multirow[t]{2}{*}{ Question } & \multicolumn{3}{|c|}{ Responses $(n=186)$} \\
\hline & & Yes & No & Not sure \\
\hline \multirow[t]{5}{*}{ A } & $\begin{array}{l}\text { Do you think vaccinations (overall) are important } \\
\text { for the protection of public health? }\end{array}$ & $80.60 \%$ & $5.40 \%$ & $14.00 \%$ \\
\hline & $\begin{array}{l}\text { Do you think getting vaccine is a good way to } \\
\text { protect yourself from diseases? }\end{array}$ & $75.30 \%$ & $9.70 \%$ & $15.10 \%$ \\
\hline & Do you think overall vaccines are effective? & $69.90 \%$ & $5.40 \%$ & $24.70 \%$ \\
\hline & Do you think overall vaccines are safe? & $59.10 \%$ & $9.70 \%$ & $31.20 \%$ \\
\hline & Did you take seasonal flu vaccine before? & $66.70 \%$ & $26.90 \%$ & $6.50 \%$ \\
\hline \multirow[t]{2}{*}{ B } & $\begin{array}{l}\text { Are you confident about the scientific venting } \\
\text { processes for the novel coronavirus/ COVID-19 vaccine? }\end{array}$ & $46.20 \%$ & $12.90 \%$ & $40.90 \%$ \\
\hline & $\begin{array}{l}\text { If a vaccine for coronavirus/ COVID-19 becomes available } \\
\text { in Saudi Arabia and being recommended, do you agree } \\
\text { to take it? }\end{array}$ & $55.90 \%$ & $10.80 \%$ & $33.30 \%$ \\
\hline
\end{tabular}


differences of COVID-19 vaccine acceptance across the different socio-demographic characteristics. Mann-Whitney test indicated that the acceptance of vaccination was higher in male than female participants $(p<0.001)$. Kruskal-Wallis test showed no statistically significant difference among different age groups and different educational levels in the uptake of COVID-19 vaccine with p-values of 0.37 and 0.77 respectively. However, significant difference was detected across different job positions at university of Jeddah, $p<0.001$ (Table 4).

\section{DISCUSSION}

This study aimed to understand the general level of awareness, practice, and attitude towards the COVID-19 disease as well as new vaccine acceptance, among health field community (healthcare workers, health fields teaching staff and students) at University of Jeddah,

a) COVID-19 Symptoms \& signs

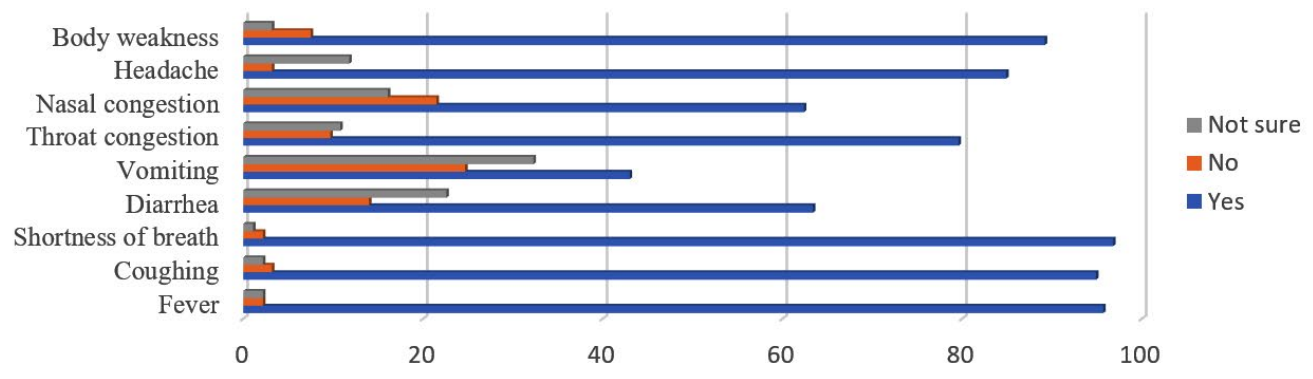

b) Protective measures

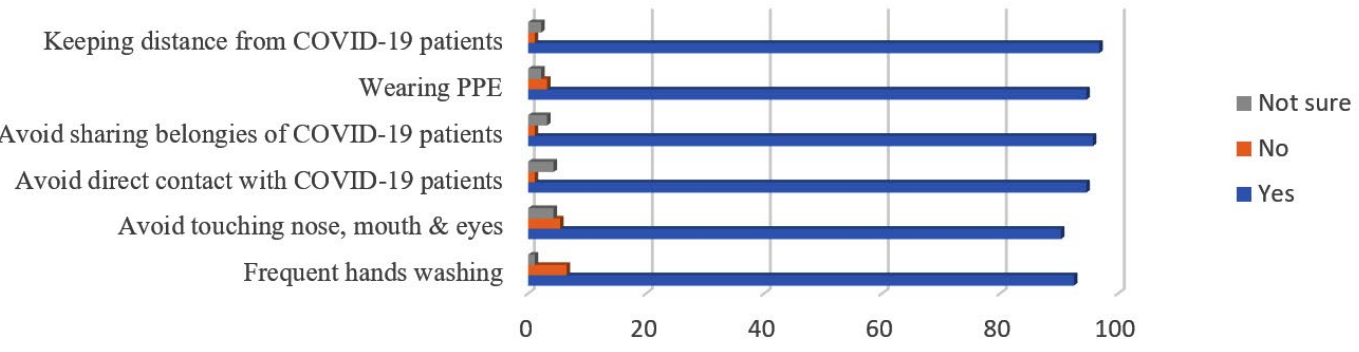

c) Health \& safety precautions

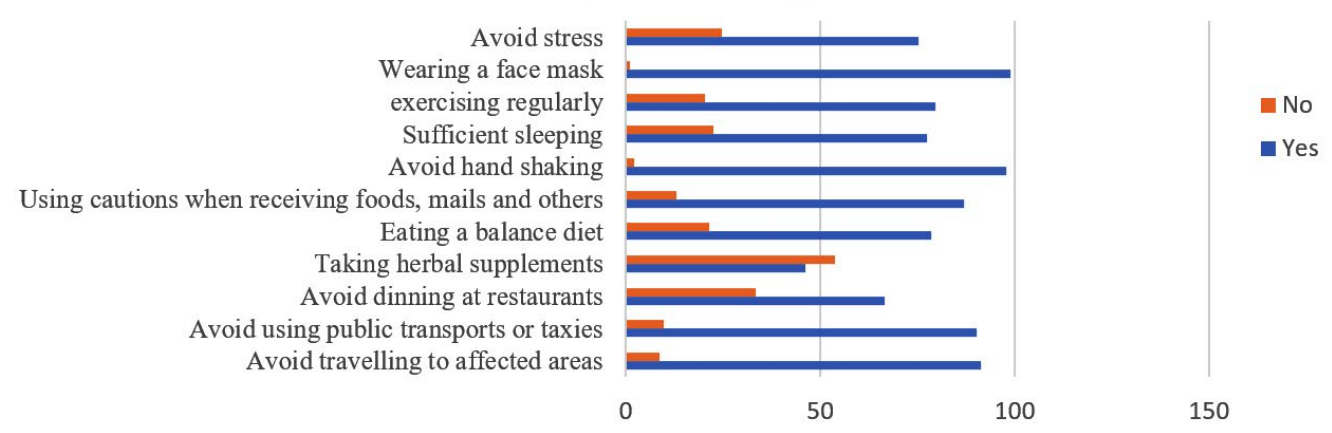

Fig. 1. Level of awareness of participants regarding COVID-19: a) symptoms and signs, b) protective measures, and c) health and safety precautions that people had to follow to reduces the risk of infection. 
located at Jeddah - KSA. Regarding participants knowledge about the virus, almost $80 \%$ showed well understanding regarding the scientific name of the virus causing COVID-19 and a considerable percentage $(58 \%)$ were aware of the cause of COVID-19. This good level of awareness is not surprising, and this can be explained by the fact that all participants in this study belong to health fields.

The outcome regarding awareness about COVID-19 symptoms and signs revealed that the majority of participants had an excellent level of knowledge that shortness of breath (96.8\%), fever (95.7\%), coughing (94.9\%), body weakness (89.2\%) and headache (84.9\%) are the common symptoms of the disease. However, less common symptoms (diarrhoea and vomiting) were less acknowledged. These levels of symptoms awareness agree with that reported by Al-Dossary et al. ${ }^{17}$ and Tripathi et al. ${ }^{18}$ who reported closely similar level of awareness among population of nurses in five regions of Saudi Arabia and healthcare workers in the west of Saudi Arabia, respectively. Furthermore, the level of symptoms awareness among participants is also found like other studies conducted by Karasneh et al. ${ }^{19}$ and Khader et al. ${ }^{20}$ among Jordanian pharmacists and dentists, respectively.

Personal protective as well as workplace safety measures against COVID-19 infection such as social distancing, wearing personal protective equipment, frequent hands washing, and several protective measures were also studied. More than $90 \%$ of participants had a good level of awareness, attitude, and practice toward protecting themselves from the disease. These findings affirm previous studies among nurses ${ }^{17}$, healthcare workers ${ }^{18}$, and general population ${ }^{21}$ in Saudi Arabia, healthcare workers and students ${ }^{22}$ in India, dentists ${ }^{20}$ and eye care providers ${ }^{23}$ in Jordan. The availability of various information from $\mathrm{MOH}$ and the fact that the study participants were well-educated and belong to the health system contributed to this high level of awareness and good preventive

Table 4. Responses of vaccine acceptance across demographic characteristics of participants

\begin{tabular}{|c|c|c|c|c|c|c|}
\hline \multirow[t]{2}{*}{ Variable } & \multirow[t]{2}{*}{ Description } & \multirow[t]{2}{*}{$\mathrm{N}$} & \multicolumn{3}{|c|}{$\begin{array}{l}\text { If a vaccine for coronavirus/ COVID-19 } \\
\text { becomes available in Saudi Arabia and being } \\
\text { recommended, do you agree to take it? }\end{array}$} & \multirow[t]{2}{*}{$\begin{array}{l}\text { Test value } \\
\mathrm{p} \text { - value }\end{array}$} \\
\hline & & & $\begin{array}{l}\text { Yes } \\
(n=104)\end{array}$ & $\begin{array}{l}\text { Not sure } \\
(n=62)\end{array}$ & $\begin{array}{l}\text { No } \\
(n=20)\end{array}$ & \\
\hline \multirow[t]{2}{*}{ Gender } & Males & 136 & $88(64.7 \%)$ & $40(29.4 \%)$ & $8(5.9 \%)$ & $Z=-4.37$ \\
\hline & Females & 50 & $16(32 \%)$ & $22(44 \%)$ & $12(24 \%)$ & $\mathrm{P}<0.001^{*}$ \\
\hline Age & $18-24$ & 90 & $50(55.6 \%)$ & $28(31.1 \%)$ & $12(13.3 \%)$ & $\mathrm{H}=4.31$ \\
\hline groups & $25-31$ & 20 & $8(40 \%)$ & $12(60 \%)$ & $0(0 \%)$ & $P=0.37$ \\
\hline \multirow{4}{*}{ (years) } & $32-38$ & 30 & $16(53.4 \%)$ & $10(33.3 \%)$ & $4(13.3 \%)$ & \\
\hline & $39-46$ & 32 & $22(68.75 \%)$ & 10 & $0(0 \%)$ & \\
\hline & $\geq 47$ & 14 & $8(57.1 \%)$ & $(31.25 \%)$ & $4(28.6 \%)$ & \\
\hline & & & & $2(14.3 \%)$ & & \\
\hline \multirow{5}{*}{$\begin{array}{l}\text { Education } \\
\text { level }\end{array}$} & High school & 20 & 12 (60\%) & $6(30 \%)$ & $2(10 \%)$ & $H=1.80$ \\
\hline & Diploma & 4 & $2(50 \%)$ & $0(0 \%)$ & $2(50 \%)$ & $P=0.77$ \\
\hline & Bachelor's & 78 & $40(51.3 \%)$ & 30 (38.4\%) & $8(10.3 \%)$ & \\
\hline & Masters & 18 & $10(58.6 \%)$ & $8(44.4 \%)$ & $0(0 \%)$ & \\
\hline & PhD or equivalent & 66 & $40(60.6 \%)$ & $18(27.3 \%)$ & $8(12.1 \%)$ & \\
\hline Position & Teaching staff & 34 & $30(88.2 \%)$ & $4(11.8 \%)$ & $0(0 \%)$ & $H=26.35$ \\
\hline \multirow[t]{4}{*}{ at UJ } & (medicine) & 36 & $14(38.9 \%)$ & $14(38.9 \%)$ & $8(22.2 \%)$ & $P<0.001^{*}$ \\
\hline & Teaching staff (AMS) & 6 & $6(100 \%)$ & $0(0 \%)$ & $0(0 \%)$ & \\
\hline & Healthcare workers & 6 & $2(40 \%)$ & $4(60 \%)$ & $0(0 \%)$ & \\
\hline & Lab technicians & 104 & $52(50 \%)$ & $40(38.5 \%)$ & $12(11.5 \%)$ & \\
\hline
\end{tabular}

* significant; $\mathrm{Z}=$ Mann-Whitney test value; $\mathrm{H}=$ Kruskal-Wallis test value 
practice. Regarding additional health and safety precautions that people intended to follow during the pandemic and that were announced by the official platforms ${ }^{24}$, the results showed that sufficient sleeping, eating balanced diet, regular exercise and avoiding stress were followed by more than three-fourth of participants. However, taking herbal supplements were acknowledged by less than half of participants. These findings were in accordance with that reported by several studies $^{25-27}$ that stated supplements were relatively slender in prevention, thus, less acknowledge.

Vaccination is considered one of the most important scientific advances in public health. It is responsible for the control of several infectious diseases; however, its acceptability is varied from region to region due to differences in geographic location, ethnicity, development, and contextual human behavior ${ }^{28-30}$.

Healthcare workers and health professionals' attitude towards vaccines is important determinants of their own vaccine acceptance and their likelihood of recommending vaccines to others ${ }^{31}$. Up to date, few studies were conducted to scout about the intention to uptake the COVID-19 vaccine among healthcare workers and health professions worldwide. However, out of the total number of participants, $56 \%$ agreed to uptake the vaccine and around $44 \%$ were refused or not sure to uptake it. The current acceptance percentage is lower than that reported by French healthcare workers ${ }^{32}$ which reached $75 \%$ and extremely higher than that reported in Democratic Republic of Congo ${ }^{31}$ which is, equal to $27.7 \%$. On the other hand, the present results were found similar to that reported by other studies conducted in Saudi Arabia ${ }^{33}$, China ${ }^{34}$ and USA ${ }^{35}$ which reported percentages of $64.7 \%, 56.6 \%$ and $67 \%$ among general population respectively.

Garcia and $\mathrm{Cerda}^{36}$ concluded that the personal decision of either to uptake or refuse the vaccine against COVID-19 is multifactorial and depends on availability of the effective vaccine, accessibility to the vaccine, perceived health risk, experience with other vaccines and sociodemographic factors. According to this, result from the current study yielded that $68.3 \%$ of those who hesitated to uptake the COVID-19 vaccine gave the reason that the vaccine may cause bothersome unacceptable side effects and $29.3 \%$ claimed that the vaccine will not be safe. Similar reasons against uptake of COVID-19 among healthcare workers (mainly the fear of risk of vaccine) were reported by other studies among healthcare workers ${ }^{31,32}$.

Results showed no significant different between age groups in term of COVID-19 vaccine uptake. However, Participants aged between 25 and 31 years of old were less accepting the vaccine compared to the rest of age groups studied. On the other hand, $88 \%$ of medicine teaching staff and $100 \%$ of healthcare workers reported that COVID-19 vaccine is effective in controlling the disease compared to other group studied. The results partially agreed Kabamba et al. ${ }^{31}$ who found that older age and occupation were significantly associated with the willing to uptake the vaccine in Democratic Republic of Congo. They justified this by the fact that older adults are particularly vulnerable to worse outcomes due to

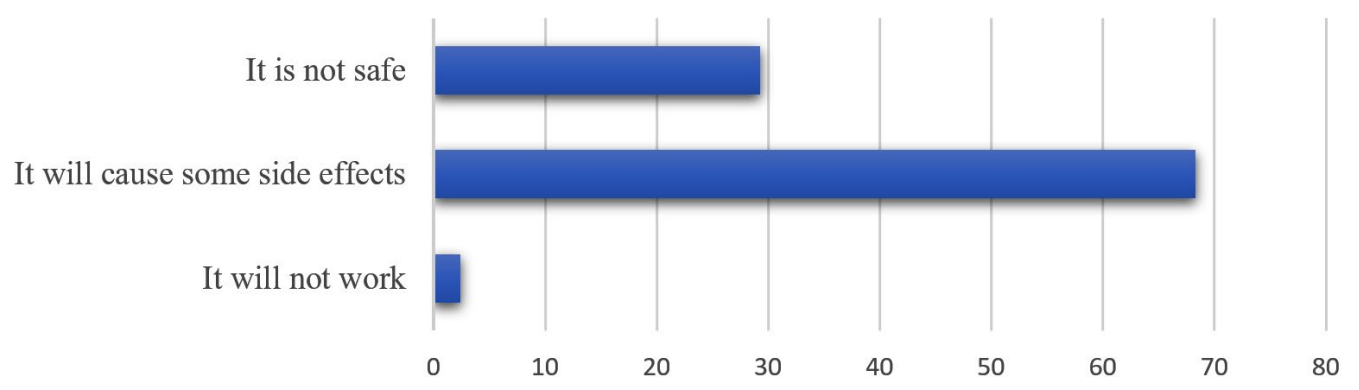

Percentage

Fig. 2. Participant's reasons of rejecting or hesitancy to take the vaccine $(n=82)$. 
COVID-19 infection. Gender was found significantly associated with the decision of the uptake the vaccine in the current study which agreed the results reported by several studies which stated the variation in gender in accepting COVD-19 vaccine ${ }^{31}$ and other vaccines ${ }^{37,38}$ with the outcome that men were more accepted to get vaccinated compared to women and attributed their outcome to an increased risk perception of disease in men compared to women.

\section{CONCLUSION}

This study showed that University of Jeddah health field community (healthcare workers, teaching staff and students) have excellent level of knowledge about COVID-19 symptoms and good general attitude towards personal protection measures against the pandemic. Despite this high level of awareness, the study showed medium acceptance level of COVID-19 vaccine and majority of those who hesitated to uptake the vaccine was fear from getting unacceptable side effects post vaccination. So, health educational programs are needed to increase the acceptance rate of vaccine among this segment of society which will reflect positively on the whole society.

The participants' poor response to the survey may be viewed as a shortcoming for the present study. However, this could be attributed to difficulty communicating with participants remotely in the existence of the pandemic.

\section{ACKNOWLEDGMENTS}

I would like to express my grateful thanks to University of Jeddah, and the health field community for participating in this study. I am also grateful to Dr. Mustafa Abdu for providing assistance on bioinformatics analysis and Dr. Jamel Matwa for English editing of the manuscript.

\section{FUNDING}

None.

\section{DATA AVAILABILITY}

The datasets generated during and/or analyzed during the current study are available from the corresponding author on reasonable request.

\section{ETHICS STATEMENT}

This article does not contain any studies with human participants or animals performed by the author.

\section{REFERENCES}

1. Chinese Center for Disease Control and Prevention. Epidemic Update and Risk Assessment of 2019 Novel Coronavirus 2020. 2020. http://www.chinacdc.cn/ yyrdgz/202001/P020200128523354919292

2. World Health Organization. Coronavirus disease 2019 (COVID-19): situation report, 72. World Health Organization. 2020. https://www.who.int/ emergencies/diseases/novel-coronavirus-2019/ situation-reports

3. Centre for Disease Control and Prevention. Coronavirus Disease 2019 (COVID 19) [Internet]. 2020. https:// www.cdc.gov/coronavirus/2019-ncov/about/index. html

4. CDC. Coronavirus Disease 2019 (COVID-19) Transmission. Centers for Disease Control and Prevention. Published March 17, 2020. https:// www.cdc.gov/coronavirus/2019-ncov/prepare/ transmission.html.

5. Chan JF, Yuan S, Kok KH, et al. A familial cluster of pneumonia associated with the 2019 novel coronavirus indicating person-to-person transmission: a study of a family cluster. The Lancet. 2020;395(10223):514-523. doi:10.1016/S0140-6736(20)30154-9

6. Casanova LM, Jeon S, Rutala WA, Weber DJ, Sobsey $M D$. Effects of air temperature and relative humidity on coronavirus survival on surfaces. Appl Environ Microbiol. 2010;76(9):2712-2717. doi: 10.1128/ AEM.02291-09

7. Kampf G, Todt D, Pfaender S, Steinmann E. Persistence of coronaviruses on inanimate surfaces and its inactivation with biocidal agents. J Hosp Infect. 2020;104(3):246-251. doi: 10.1016/j.jhin.2020.01.022

8. Bai $Y$, Yao L, Wei T, et al. Presumed asymptomatic carrier transmission of COVID-19. JAMA. 2020;323(14):14061407. doi:10.1001/jama.2020.2565

9. Wang D, Hu B, Hu C, et al. Clinical characteristics of 138 hospitalized patients with 2019 novel coronavirus-infected pneumonia in Wuhan, China. JAMA. 2020:323(11):1061-1069. doi: 10.1001/ jama.2020.1585

10. Huang C, Wang Y, Li X, et al. Clinical features of patients infected with 2019 novel coronavirus in Wuhan, China. The Lancet. 2020;395:497-506. doi: 10.1016/S01406736(20)30183-5

11. Novel CPERE. The epidemiological characteristics of an outbreak of 2019 novel coronavirus diseases (COVID-19) in China. Zhonghua Liu Xing Bing Xue Za Zhi. 2020;41(2):145-151. doi: $10.3760 / \mathrm{cma}$.j.is sn.0254-6450.2020.02.003

12. Khitam Al Amir S. COVID-19: Saudi Arabia Expects 200,000 Cases If Measures Not Followed. Gulfnews. com. 2020. https://gulfnews.com/world/gulf/saudi/ covid-19-saudi-arabia-ex pects-200000-cases-ifmeasures-not-followed-1.1586263454490 (accessed Jan 2021) 
13. Algaissi AA, Alharbi NK, Hassanain M, Hashem AM. Preparedness and response to COVID-19 in Saudi Arabia: Building on MERS experience. $J$ Infect Public Health. 2020;13(6):834-838. doi: 10.1016/j. jiph.2020.04.016

14. World Health Organization. Report of the SAGE Working Group on Vaccine Hesitancy. World Health Organization 2014. [Cited Dec 2020]. Available at: https://www.who.int/immunization/sage/sage_wg_ vaccine_hesitancy_apr12/en/

15. Quinn SC, Jamison AM, An J, Hancock GR, Freimuth VS. Measuring vaccine hesitancy, confidence, trust and flu vaccine uptake: Results of a national survey of White and African American adults. Vaccine. 2019;37(9):1168-1173. doi: 10.1016/j. vaccine.2019.01.033

16. Lazarus JV, Ratzan S, Palayew A, et al. COVIDSCORE: A global survey to assess public perceptions of government responses to COVID-19 (COVIDSCORE-10). PLOS ONE. 2020;15(10): e0240011. doi: 10.1371/journal.pone.0240011

17. Al-Dossary R, Alamri M, Albaqawi $\mathrm{H}$, et al. Awareness, Attitudes, Prevention, and Perceptions of COVID-19 Outbreak among Nurses in Saudi Arabia. Int J Environ Res Public Health. 2020;17(21):8269. doi: 10.3390/ ijerph17218269

18. Tripathi R, Alqahtani SS, Albarraq AA, et al. Awareness and Preparedness of COVID-19 Outbreak Among Healthcare Workers and Other Residents of South-West Saudi Arabia: A Cross-Sectional Survey. Front Public Health. 2020;8:482. doi: 10.3389/fpubh.2020.00482

19. Karasneh R, Al-Azzam S, Muflih S, Soudah O, Hawamdeh $S$, Khader Y. Media's effect on shaping knowledge, awareness risk perceptions and communication practices of pandemic COVID-19 among pharmacists. Res Social Adm Pharm. 2021;17(1):1897-1902. doi: 10.1016/j.sapharm.2020.04.027

20. Khader Y, Al Nsour M, Al-Batayneh OB, et al. Dentists' Awareness, Perception, and Attitude Regarding COVID-19 and Infection Control: Cross-Sectional Study Among Jordanian Dentists. JMIR Public Health Surveill. 2020;6(2):e18798. doi: 10.2196/18798 doi: $10.2196 / 18798$

21. Bazaid AS, Aldarhami A, Binsaleh NK, Sherwani S, Althomali OW. Knowledge and practice of personal protective measures during the COVID-19 pandemic: A cross-sectional study in Saudi Arabia. PLOS ONE. 2020;15(12): e0243695. doi: 10.1371/journal. pone. 0243695

22. Singh AK, Agrawal B, Sharma A, Sharma P. COVID-19: Assessment of knowledge and awareness in Indian society. J Public Affairs. 2020;20(4):e2354. doi: 10.1002/pa.2354

23. Jammal HM, Alqudah NM, Khader Y. Awareness, Perceptions, and Attitude Regarding Coronavirus Disease 2019 (COVID-19) Among Ophthalmologists in Jordan: Cross-Sectional Online Survey. Clin Ophthalmol. 2020;14:2195-2202. doi: 10.2147/OPTH.S260460

24. WHO, "WHO Situation reports - Coronavirus disease 2019," 2020. [Online]. https://www.who. int/emergencies/diseases/novel-coronavirus-2019/ situation-reports
25. Davies E, McConn-Palfreyman W, Williams JM, Lovell GP. The Impact of COVID-19 on Staff Working Practices in UK Horseracing. Animals (Basel). 2020;10(11):2003. doi:10.3390/ani10112003

26. Taghizadeh-Hesary F, Akbari H. The powerful immune system against powerful COVID-19: A hypothesis. Med Hypotheses. 2020;140:109762. doi:10.1016/j. mehy.2020.109762

27. Grant WB, Lahore H, McDonnell SL, et al. Evidence that Vitamin D Supplementation Could Reduce Risk of Influenza and COVID-19 Infections and Deaths. Nutrients. 2020;12(4):988. doi:10.3390/nu12040988

28. Musa D, Schulz R, Harris R, Silverman M, Thomas SB. Trust in the health care system and the use of preventive health services by older black and white adults. Am J Public Health. 2009;99(7):1293-1299. doi:10.2105/AJPH.2007.123927

29. Larson HJ, Jarrett C, Eckersberger E, Smith DM, Paterson $\mathrm{P}$. Understanding vaccine hesitancy around vaccines and vaccination from a global perspective: a systematic review of published literature, 20072012. Vaccine. 2014;32(19):2150-2159. doi:10.1016/j. vaccine.2014.01.081

30. Dube E. Addressing vaccine hesitancy: the crucial role of healthcare providers. Clin Microbiol Infect. 2017;23(5):279-280. doi:10.1016/j.cmi.2016.11.007

31. Nzaji MK, Ngombe LK, Mwamba GN, et al. Acceptability of Vaccination Against COVID-19 Among Healthcare Workers in the Democratic Republic of the Congo. Pragmat Obs Res. 2020;11:103-109. doi: 10.2147/ POR.S271096

32. Gagneux-Brunon A, Detoc M, Bruel S, et al. Intention to get vaccinations against COVID-19 in French healthcare workers during the first pandemic wave: a cross sectional survey. J Hosp Infect. 2021;108:168-173. doi:10.1016/j.jhin.2020.11.020

33. Al-Mohaithef M, Padhi BK. Determinants of COVID-19 Vaccine Acceptance in Saudi Arabia: A Web-Based National Survey. J Multidiscip Healthc. 2020;13:16571663. doi:10.2147/JMDH.S276771

34. Lin $Y, H u Z$, Zhao Q, Alias H, Danaee M, Wong LP. Understanding COVID-19 vaccine demand and hesitancy: A nationwide online survey in China. PLoS Negl Trop Dis. 2020;14(12):e0008961. doi:10.1371/ journal.pntd.0008961

35. Malik AA, McFadden SM, Elharake J, Omer SB. Determinants of COVID-19 vaccine acceptance in the US. EClinical Medicine. 2020;26:100495. doi: 10.1016/j.eclinm.2020.100495

36. Garcia LY, Cerda AA. Acceptance of a COVID-19 vaccine: A multifactorial consideration. Vaccine. 2020;38(48):7587. doi: 10.1016/j.vaccine.2020.10.026

37. Detoc M, Bruel S, Frappe P, Tardy B, Botelho-Nevers $E$, Gagneux-Brunon A. Intention to participate in a COVID-19 vaccine clinical trial and to get vaccinated against COVID-19 in France during the pandemic. Vaccine. 2020;38(45):7002-7006. doi:10.1016/j. vaccine. 2020.09.041

38. Jones $M$, Cook R. Intent to receive an HPV vaccine among university men and women and implications for vaccine administration. J Am Coll Health. 2008;57(1):23-32. doi:10.3200/JACH.57.1.23-32 